\title{
A New Homogenized Climate Division Precipitation Dataset for Analysis of Climate Variability and Climate Change
}

\author{
D. BRent MCRoberts AND JOHN W. NIELSEN-GAMMON \\ Department of Atmospheric Sciences, Texas A\&M University, College Station, Texas
}

(Manuscript received 18 August 2010, in final form 6 December 2010)

\begin{abstract}
A new homogeneous climate division monthly precipitation dataset [based on full network estimated precipitation (FNEP)] was created as an alternative to the National Climatic Data Center (NCDC) climate division dataset. These alternative climate division monthly precipitation values were estimated using an equal-weighted average of Cooperative Observer Program stations that contained serially complete time series. Missing station observations were estimated by a procedure that was optimized through testing on U.S. Historical Climate Network stations. Inhomogeneities in the NCDC dataset arise from two principal causes. The pre-1931 estimation of NCDC climate division monthly precipitation from statewide averages led to a significant time series discontinuity in several climate divisions. From 1931 to the present, NCDC climate division averages have been calculated from a subset of available station data within each climate division, and temporal changes in the location of available stations have caused artificial changes in the time series. The FNEP climate division dataset is recommended over the NCDC dataset for studies involving climate trends or long-term climate variability. According to the FNEP data, the 1895-2009 linear precipitation trend is positive across most of the United States, and trends exceed $10 \%$ per century across the southern plains and the Corn Belt. Remaining inhomogeneities from changes in gauge technology and station location may be responsible for an artificial trend of $1 \%-3 \%$ per century.
\end{abstract}

\section{Introduction}

The National Climatic Data Center (NCDC) subdivides each of the 48 conterminous states in the United States into climate divisions, regions considered to contain a relatively homogeneous climate within their boundaries (Guttman and Quayle 1996). Monthly values of temperature, precipitation, and derived climate products are calculated for each climate division for the period 1895 present. NCDC climate division average precipitation (CDP) values are calculated on a monthly basis, with each climate division containing a record dating back to 1895 . Prior to 1931, these monthly values were estimated from statewide values using a linear regression equation (Guttman and Quayle 1996). From 1931 to the present, climate division values represent an equal-weighted average of those stations reporting both temperature and

Corresponding author address: D. Brent McRoberts, Dept. of Atmospheric Sciences, Texas A\&M University, M.S. 3150, College Station, TX 77843-3150.

E-mail: mcrobert@tamu.edu precipitation within a given climate division's boundary (Guttman and Quayle 1996).

Apparently because of their spatial completeness, geographic resolution, and ease of use, climate division data have become popular for a wide variety of applications. Monthly climate division precipitation data are widely used in long-term analyses of precipitation (e.g., Karl and Knight 1998; Kunkel et al. 1999; Leathers et al. 2000; McCabe et al. 2004; Goodrich and Ellis 2006; Easterling et al. 2007; Kurtzman and Scanlon 2007; Grantz et al. 2007; Grundstein 2008; Seager et al. 2009). Additionally, drought indicators such as the Palmer drought severity index (PDSI) use historical climate division data to make real-time assessments. The PDSI and other drought indicators are sensitive to changes in the mean and variance of historical climate division data and rely on accurate historical data to correctly diagnose drought. But there are recognized fundamental flaws that make the climate division data unreliable for these purposes.

A major weakness of the currently available climate division dataset is that the network of stations used to calculate climate division values is not constant over 
time (Guttman and Quayle 1996). This can be especially troublesome in the western United States, where station elevations within a single climate division can vary by $1000 \mathrm{~m}$ or more and the land area encompassed by climate divisions can be tens of thousands of square kilometers (Sheppard et al. 2002). Climatological average values of annual precipitation at different stations within a climate division can easily vary by a factor of 5 or more. In climate divisions with spatially inhomogeneous precipitation climates, changes in the configuration of stations can cause spurious long-term precipitation trends and spurious short-term precipitation variations (Keim et al. 2005; Allard et al. 2008).

Because climate division data are so widely used in precipitation analyses despite these shortcomings, there is a clear scientific need to quantify the errors introduced by climate division inhomogeneities and to develop a climate division precipitation dataset not subject to these spurious biases. Here we focus on precipitation because the impacts of spatial variations of precipitation are relatively large and station temperature records may themselves possess important inhomogeneities (Pielke et al. 2007). Application of station-based homogeneity corrections (Menne et al. 2009) to Cooperative Observer Program (COOP) stations will enable a similar analysis to be performed for temperature.

One solution for creating an alternative climate division dataset is to compute climate division averages with a fixed network of serially complete stations from 1895 to the present. Keim et al. (2005) and Allard et al. (2008) used U.S. Historical Climate Network (USHCN) stations with continuous records in constructing alternative climate division time series for New England and the southeastern United States, respectively. However, there are only 1221 stations in the USHCN version-2 dataset across the 344 U.S. climate divisions (Menne et al. 2009), and only 27 are truly serially complete, the other 1194 having one or more estimated monthly values that fill data gaps. The USHCN is a subset of long-term stations in the National Oceanic and Atmospheric Administration's (NOAA) COOP network, which contains more than 24000 stations.

Because a USHCN-only climate division dataset would exclude so many other COOP observations, this study adopts an alternative approach that uses as many COOP observations as possible. Estimates based on neighboring stations are used to extend the record of each viable COOP station to fill the complete period 1895-present. This study creates an improved NCDC climate division dataset by estimating missing monthly precipitation values at COOP stations. The end result is a fixed network of COOP stations in each climate division, whose observed or estimated values may then be used to compute temporally homogeneous climate division averages of precipitation.

Several procedures for interpolating the missing data were explored, each using data available at nearby stations. After the optimal interpolation procedure was finalized following testing on USHCN stations, estimates for missing data were computed and merged with the real values at each COOP station. The alternative climate division dataset was created from 1895 to 2009 using the merged time series at each COOP station. Section 2 explains the datasets used and created, section 3 describes the testing done to create the optimal interpolation scheme, section 4 compares long-term trends in the NCDC climate division dataset with those in our alternative dataset, section 5 considers the reduction in variance associated with the homogenization technique, and section 6 summarizes the results.

\section{Data and terminology}

The COOP and USHCN precipitation data were obtained from NCDC. The data provided by NCDC have passed automated quality control processing and are deemed suitable for this study. COOP stations that double as USHCN stations use data from the USHCN version-2 (USHCN-v2) dataset, which has undergone additional, extensive quality control and has estimated missing values using the Fill Missing Original Data in the Network (FILNET) adjustment procedure (Menne et al. 2009).

Of the 24335 COOP stations, roughly $2 \%$ included duplicate data reported under more than one station identifier. To avoid double weighting, the COOP data from NCDC were screened and stations with multiple COOP identification numbers were combined into one station record. Other COOP stations, mostly those whose period of record ended prior to 1965 , were associated with an incorrect climate division number, probably because of changes in climate division boundaries over time. Stations were reassigned to their proper climate divisions based on visual inspection of mapped station locations relative to climate division boundaries.

Very few COOP stations are complete over the period 1895-2009. The key step in this analysis is to fill in the gaps and artificially extend the record of COOP stations to span the entire period.

An interpolation procedure (to be described below) replaces the missing monthly values in each COOP station time series with estimated values. The resulting dataset, consisting of observed values where available and estimated values where necessary, will be called the "merged" COOP dataset. The station for which an estimated value is needed will be called the "target" station, and other nearby stations used to estimate the value will be called "neighbors." 
The existing climate division precipitation dataset from NCDC will be called CDP data. "Homogenized" climate division precipitation data can take many forms, depending on the intended use of the data. For example, the Parameter-Elevation Regressions on Independent Slopes Model (PRISM) dataset (Daly et al. 2002) consists of spatially interpolated data that may be homogeneous with respect to the climatological mean, depending on the accuracy of the interpolation, and can be aggregated into climate division data that represent reasonable estimates of the true mean within a climate division. However, as the number of stations within a climate division changes, the expected variance of a climate division time series would change as well, and for some applications it may be appropriate to adjust the time series to homogenize the variance as well.

For comparison and integration with current and future CDP data, it may be useful to create a homogenized dataset using estimates only at present-day station locations. However, such an approach neglects actual data from past stations that could be used to provide a more accurate value for the historic climate division values. Here, we choose to use all available actual data at COOP stations that have enough data to satisfy a minimum data criterion that will be discussed in section 3 .

The resulting climate division precipitation values [full network estimated precipitation (FNEP)] will have the following characteristics: (i) values computed using all available COOP data within a climate division, including USHCN stations; (ii) expected (mean) values that are homogeneous through time; (iii) expected values that are specific to the station location distribution and therefore do not necessarily represent an accurate estimate of the true spatial mean precipitation; (iv) variance that is inhomogeneous through time depending on the proportion of actual versus estimated data values.

\section{Testing and selection of estimation procedures}

\section{a. Normalization}

In general, an estimated precipitation value is expressed as a weighted average of neighboring observations. This study tests some simple interpolation procedures that calculate the weights directly from the geographical or statistical properties of the target and neighbor stations. The simplest possible approach is to apply equal weights to some number of neighbor stations. However, the climatological precipitation normal at neighboring stations can be different than at a target station, so using raw precipitation values in the estimation procedure is not appropriate. Departures from normal precipitation tend to exhibit greater spatial coherence than normals themselves
(Jones and Hulme 1996), so we estimate the departure from normal at target stations using a weighted average of the departures from normal at neighboring stations.

Departures from normal may be expressed as a difference (observed minus normal) or as a ratio (observed divided by normal). Ratios are more commonly used for precipitation, and are recommended by New et al. (1999), Peterson et al. (1998), and Alexandersson (1986). We shall refer to observed precipitation divided by the corresponding normal precipitation as normalized precipitation and identify the weights as the coefficients applied to the normalized precipitation values. So, for example, the normal ratio (NR) method (Paulhus and Kohler 1952) uses an unweighted average of the normalized precipitation at three neighbor stations:

$$
\frac{P_{T k}}{N\left(P_{T}\right)}=\sum_{i=1}^{3}\left[\frac{P_{i k}}{N\left(P_{i}\right)}\right],
$$

where $P_{i k}$ is the observed precipitation at the $i$ th neighbor station during month $k, N\left(P_{i}\right)$ is the normal value of precipitation during that month at station $i$, and the subscript $T$ refers to the target station. More generally,

$$
P_{T k}=\frac{\sum_{i=1}^{n}\left[w_{i} \frac{N_{i T}\left(P_{T}\right)}{N_{i T}\left(P_{i}\right)} P_{i k}\right]}{\sum_{i=1}^{n} w_{i}}
$$

with $w_{I}=1$ (hence the name "normal ratio") and the number of stations $n=3$. Equation (2) has been written to allow the definition of normal precipitation $N_{i T}(P)$ to depend on the particular combination of target and neighbor station, as explained below.

Most studies use normals computed from a reference interval (usually 30 years) during which a large fraction of stations reported. However, there is no common 30 -year period of overlap for all COOP stations. Because of inconsistencies in the data availability at COOP stations, we calculate normals using only the period of data overlap between a neighbor station and the target station. Thus the calculated normal at the target station depends upon the period of overlap with the neighbor station, and the target normal must be included within the summation bracket as in (2).

\section{b. Weighting methods}

Three simple methods for assigning weights for (2) were tested. The Young (1992) method is usually called the modified normal ratio (MNR) method, and assigns 
weights according to the square of the $t$ statistic used to estimate the significance of the correlation coefficient:

$$
w_{i}=\frac{r_{T i}^{2}(m-2)}{1-r_{T i}^{2}},
$$

where $r_{T i}$ is the correlation coefficient between the precipitation values at target station $T$ and neighbor station $i$ for a given month of the year and $m$ is the number of overlapping data values. The MNR method has been used to infer both daily and monthly precipitation (Eischeid et al. 2000; Mosmann et al. 2004; Suhaila et al. 2008; Kumar and Duffy 2009).

Several studies weight neighbor stations using an inverse distance weighting (IDW) scheme (New et al. 1999; Di Luzio et al. 2008; Serbin and Kucharik 2009) that is based purely on the geographical distance $R_{T i}$ between the target station and the neighbor station:

$$
w_{i}=\frac{1}{R_{T i}} .
$$

Sun and Peterson (2005) found an interpolation weighting scheme called inverse weighting of the squared difference (IWSD) to outperform IDW-based interpolation. The IWSD interpolation method is a completely datadriven scheme that assigns higher weights to neighbor stations that minimize the differences in the overlapping monthly precipitation data:

$$
w_{i}=\frac{m}{\sum_{j=1}^{m}\left[\frac{P_{i j}}{N_{i T}\left(P_{i}\right)}-\frac{P_{T j}}{N_{i T}\left(P_{T}\right)}\right]^{2}} .
$$

\section{c. Other considerations}

Three weighting techniques (MNR, IDW, and IWSD) were tested for their relative performance when estimating missing values. To produce quality estimations, stations considered as neighbor stations must have a sufficient amount of overlapping data with the target station. However, providing too strict a limit on the amount of overlapping data can unnecessarily eliminate useful observations. The most critical aspect of estimating a missing monthly precipitation value is choosing which neighboring station values will be used to calculate the estimate (Eischeid et al. 1995). Since the first estimation procedures for missing precipitation values were proposed (Paulhus and Kohler 1952), it has been common to limit neighboring stations to those in close proximity.

Hulme and New (1997) suggest that rigorous limitation of stations based on data availability produces better estimates in areas with a dense network of stations, but reduces the quality of estimates where spatial overage is poor. Cressman (1959) and Peterson and Easterling (1994) included only neighboring stations within a prespecified radius of the target station, while New et al. (1999) and Eischeid et al. (2000) limited neighboring stations to a prespecified number of stations closest to the target station. In our estimation procedure, stations most highly correlated to the target station were chosen as neighbor stations from among a set of candidate neighbor stations.

Note that the set of candidate neighbor stations will in general change from month to month and year to year. To be a candidate neighbor, a station must report a precipitation value for the month to be estimated as well as for a sufficient period of overlap with data reported by the target station.

\section{d. Method selection}

An interpolation method was chosen based upon the results of a pair of data withholding experiments using the complete USHCN-v2 dataset. The end result of each individual test was a serially complete time series of estimated values at each USHCN station that were compared to the observed values for the period 1971-2000, and the procedure was repeated for the period 1901-30. The rootmean-square (RMS) difference between the estimated and observed values, averaged across all months at all USHCN stations, provided a single comprehensive metric that measures the performance of the estimation procedure itself.

This test was applied to the following permutations of estimation procedure: weighting method $=\{$ MNR, IDW, IWSD $\}$, minimum overlap $=\{5,10,15,20$ years $\}$, candidate neighbors $=\{5,10,15,20,25$ stations $\}$, and neighbors $=\{2,4,6,8,10,13,16,19,22,25$ stations $\}$ (limited to be less than or equal to the number of candidate neighbors), for a total of 372 permutations for each of 12 months and each of the 1218 USHCN stations.

The overall RMS errors were lower for the 1901-30 period for the two data-driven weighting methods (IWSD, MNR) when averaged among all the possible permutations, despite the greater availability of nearby stations for the 1971-2000 period. Because the earlier stations tended to have a longer period of record, this suggests that the benefit of a longer calibration period outweighs the benefit of better data proximity when calibration information is used for weighting.

We combine the results of the 1901-30 testing and the 1971-2000 testing to choose a method that is effective over the entire time series, 1895-present. The IDW weighting method performed better overall for each of 
TABLE 1. Average RMSE (mm) of monthly precipitation based on the minimum years of overlap data for the IDW, IWSD, and MNR weighting methods.

\begin{tabular}{lcccc}
\hline \multirow{2}{*}{$\begin{array}{l}\text { Weighting } \\
\text { scheme }\end{array}$} & \multicolumn{4}{c}{ Min years of data overlap } \\
\cline { 2 - 5 } & 5 & 10 & 15 & 20 \\
\hline IDW & 20.0 & 20.0 & 20.1 & 20.1 \\
IWSD & 20.4 & 20.2 & 20.2 & 20.2 \\
MNR & 20.3 & 20.2 & 20.2 & 20.3 \\
\hline
\end{tabular}

the four choices of minimum overlap (Table 1), with the best performance at a minimum of 10 years of overlap. The differences in RMSE between the different overlap criteria within each weighting method in Table 1 were much smaller than the reported errors. This suggests that differences in the period of record among stations used in the FNEP dataset is not of great concern as long as each station satisfies a minimum data requirement.

This minimum overlap period effectively restricts the eligible COOP data to data from stations with at least 10 years of observations from a given month. Out of the 24335 stations in the COOP network, 12705 stations met the minimum data requirement for monthly precipitation observations and were used in the FNEP dataset.

Proceeding with weighting method = IDW and minimum overlap $=10$ years, the overall performance of each combination of number of candidate neighbors and number of actual neighbors was evaluated (Table 2). The neighbors chosen were those among the candidate neighbors whose data for a given month were most correlated to data at a given target station. The best overall performance was achieved using 13 neighboring stations from 20 candidate neighbors.

In summary, the optimal estimation procedure was found to be weighting method $=\{\mathrm{IDW}\}$, minimum overlap $=\{10$ years $\}$, candidate neighbors $=\{20$ stations $\}$, and neighbors with best correlation $=\{13$ stations $\}$. This procedure was used to create the FNEP dataset.

\section{e. Validation of estimation procedure}

The estimation of missing data at COOP stations included in the FNEP dataset calculations was validated using annual precipitation. A year of data was withheld from a COOP station, and the monthly data values were estimated using the optimal estimation procedure described above and summed to produce an annual estimate that was then compared to the observed value.

Overall, the average normalized error for estimated annual precipitation data was $9.3 \%$. Only 1 in 12 COOP stations had an average error greater than $15 \%$ (Table 3) and only 294 of the 12307 stations $(2.31 \%)$ with at least 10 years of observational data for each calendar month had an average error more than $20 \%$. In arid areas,
TABLE 2. Average monthly precipitation RMSE (mm) using the IDW weighting method for tested values of number of actual neighbors and number of candidate neighbor stations. The lowest value is in boldface.

\begin{tabular}{cccccc}
\hline \hline \multirow{2}{*}{$\begin{array}{c}\text { No. of actual } \\
\text { neighbors }\end{array}$} & 5 & 10 & 15 & 20 & 25 \\
\cline { 2 - 6 } & 5 & 22.3 & 22.5 & 22.7 & 22.7 \\
\hline 2 & 21.9 & 20.2 & 20.3 & 20.4 & 20.6 \\
4 & 20.0 & 19.5 & 19.6 & 19.7 & 19.8 \\
6 & & 19.3 & 19.3 & 19.4 & 19.5 \\
8 & & 19.3 & 19.2 & 19.3 & 19.3 \\
10 & & & 19.2 & $\mathbf{1 9 . 2}$ & 19.2 \\
13 & & & & 19.3 & 19.3 \\
16 & & & & 19.4 & 19.3 \\
19 & & & & & 19.5 \\
22 & & & & & 19.7 \\
25 & & & & &
\end{tabular}

where annual precipitation totals are relatively small, a minor variation in absolute error can sometimes represent a relatively large percentage of the total precipitation. When the normalized station errors were averaged for climate divisions, the largest average errors were found in climate divisions that rank among the driest $10 \%$ of all climate divisions (Table 4).

\section{f. Representativeness of climate division values}

The optimal interpolation procedure was used in another type of test that successively withheld the entire period of record of a single USHCN station within each climate division from both the estimation of missing data and the computation of climate division values. A good correlation between the climate division monthly precipitation values and the independent USHCN observations within the climate division implies that the climate division values properly represent the temporal precipitation variability within the climate division. For comparison, CDP values were recomputed using the standard post-1930 NCDC method but withholding single USHCN stations.

The FNEP method had a higher overall correlation for each period examined (Table 5) when averaged among the 337 USHCN stations ( 1 in each climate division, if

TABLE 3. Mean absolute normalized errors (annual precipitation) for COOP stations included in the FNEP dataset, grouped by magnitude of error.

\begin{tabular}{cc}
\hline $\begin{array}{c}\text { Annual precipitation } \\
\text { avg error (\%) }\end{array}$ & $\begin{array}{c}\text { Percentage of COOP } \\
\text { stations }(\%)\end{array}$ \\
\hline$<10$ & 67.2 \\
$10-15$ & 24.4 \\
$15-20$ & 6.1 \\
$20-25$ & 1.4 \\
$>25$ & 1.0 \\
\hline
\end{tabular}


TABLE 4. Annual precipitation normalized errors for COOP stations in the FNEP dataset, averaged over the entire climate division.

\begin{tabular}{|c|c|c|c|}
\hline \multirow[b]{2}{*}{ Climate division } & \multicolumn{2}{|c|}{ 1971-2000 climate division normals } & \multirow{2}{*}{$\begin{array}{c}\text { Avg station } \\
\text { estimation error (\%) }\end{array}$} \\
\hline & Dryness rank (out of 344 ) & Annual precipitation (mm) & \\
\hline AZ 5-southwest & 1 & 113.3 & 24.23 \\
\hline NV 3-south-central & 3 & 189.2 & 20.91 \\
\hline NV 4-extreme southern & 2 & 137.9 & 20.42 \\
\hline CO 5-Rio Grande drainage & 29 & 313.9 & 19.89 \\
\hline TX 5-trans-Pecos & 30 & 317.0 & 17.84 \\
\hline NM 5-central valley & 13 & 243.8 & 17.02 \\
\hline NV 1-northwestern & 5 & 212.6 & 16.75 \\
\hline AZ 1-northeast & 8 & 228.3 & 16.62 \\
\hline CA 7-southeast desert basins & 12 & 243.3 & 16.57 \\
\hline NM 7-southern desert & 34 & 342.6 & 16.56 \\
\hline
\end{tabular}

available) used in this test. The performance of the standard CDP method was particularly poor for 30-year periods that included data prior to 1931. According to this test, the FNEP climate division data are more representative of actual precipitation within the climate divisions than is the standard CDP data since 1931. Assuming that pre-1931 CDP data are no more accurate than post-1931 CDP data, we conclude that the FNEP climate division data are generally more representative than the standard CDP data throughout the period of record.

\section{Long-term trends}

\section{a. Comparison of long-term trends}

The FNEP (Fig. 1a) and CDP (Fig. 1b) ordinary least squares linear trends of annual precipitation for all 344 U.S. climate divisions were calculated for the period 1895-present. The trends are expressed as a percentage change per century relative to the 1895-2009 mean precipitation. In most climate divisions, the sign of the FNEP precipitation trend is the same as the sign of the CDP trend, but there are a few notable differences. The FNEP long-term trends exhibit more spatial consistency, with mostly positive trends outside of the southern Appalachian Mountains and northern Rocky Mountains. The CDP long-term trends are more erratic and have a wider range. The differences between the two trends are in many cases as large as or larger than the trends themselves. Figure 1c displays the FNEP trend minus the CDP trend for all 344 climate divisions.

There are two primary causes for major discrepancies between the FNEP and CDP long-term linear trends. Climate division data prior to 1931 are prone to biases that are the by-product of being computed from imperfect linear regressions of statewide averages. Over the entire period, the climate division averages are susceptible to biases caused by changes in the COOP stations used to calculate the equal-weighted monthly averages.

\section{b. CDP biases caused by computation from statewide averages (1895-1930)}

Differences between CDP and FNEP should be characterized by abrupt changepoints associated with changes in station distribution or methodology. Station distribution changes could take place any time during the period of record, but there was only one change in the methodology: the shift from linear regression of statewide averages to direct climate division averages beginning in 1931 (Guttman and Quayle 1996). A tendency for changepoints to occur at or about 1931 would imply that the change in methodology caused an abrupt artificial change in mean precipitation in the CDP data, which in turn would affect calculations of long-term precipitation trends.

Possible changepoints may be identified using the cumulative sum (CUSUM) method, also known as adjusted partial sums or cumulative deviations from the mean (Buishand 1982). Figure 2 shows the most prominent changepoints in the difference between CDP and FNEP annual precipitation for each of the 344 climate divisions. By far the most common changepoint year is

TABLE 5. Comparisons of the average correlation between climate division precipitation time series and withheld USHCN station data using the post-1930 CDP scheme and the FNEP scheme.

\begin{tabular}{lcc}
\hline \multicolumn{1}{c}{ Period } & CDP & FNEP \\
\hline $1901-30$ & 0.795 & 0.823 \\
$1911-40$ & 0.800 & 0.822 \\
$1921-50$ & 0.810 & 0.823 \\
$1931-60$ & 0.816 & 0.825 \\
$1941-70$ & 0.820 & 0.825 \\
$1951-80$ & 0.824 & 0.827 \\
$1961-90$ & 0.823 & 0.826 \\
$1971-2000$ & 0.820 & 0.824 \\
$1895-$ present & 0.807 & 0.821 \\
\hline
\end{tabular}


(a)

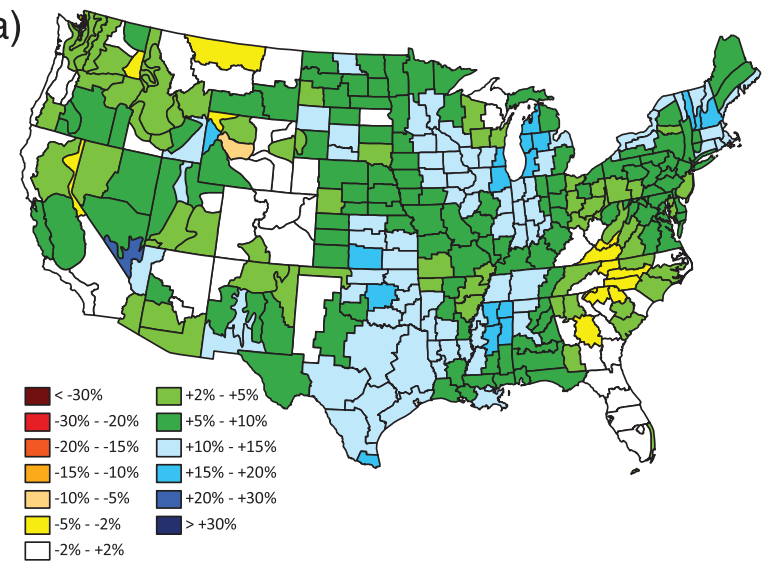

(b)

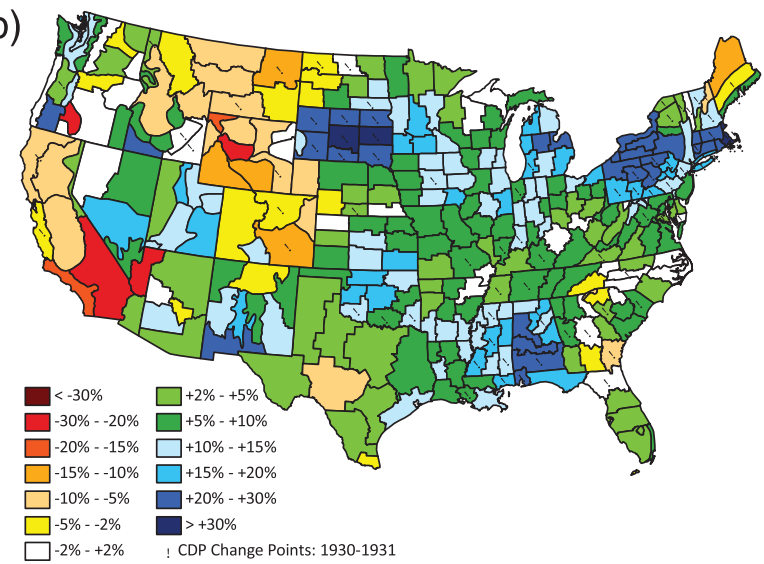

(c)

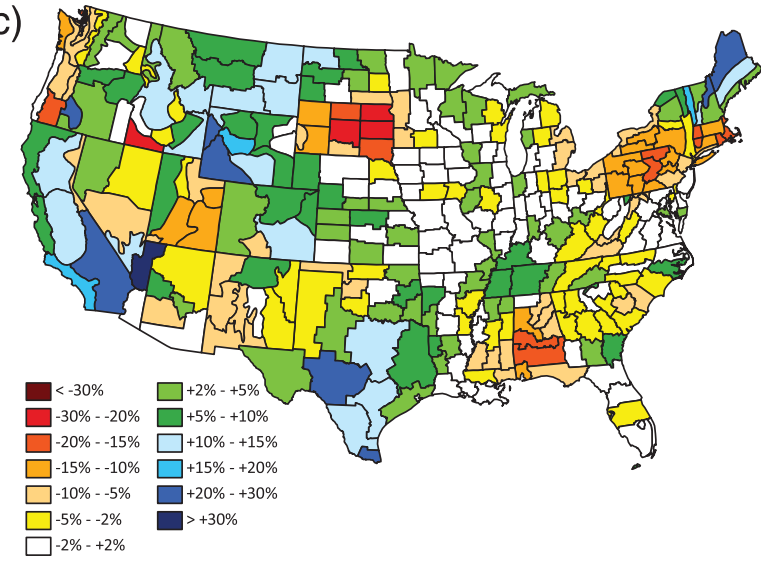

FIG. 1. Linear trends of annual precipitation from the 1895-2009 period for (a) the FNEP dataset, (b) the CDP dataset, and (c) the 1895-2009 FNEP trend minus the 1895-2009 CDP trend, all denoted as percentage change per century. Climate divisions with significant $(p<0.01)$ changepoints in either 1930 or 1931 are marked in (b).

1930, with $16 \%$ of the climate divisions exhibiting their largest apparent shift in the mean difference between that year and the next. Most of those changepoints are significant at the $99 \%$ level. An additional $6 \%$ of the

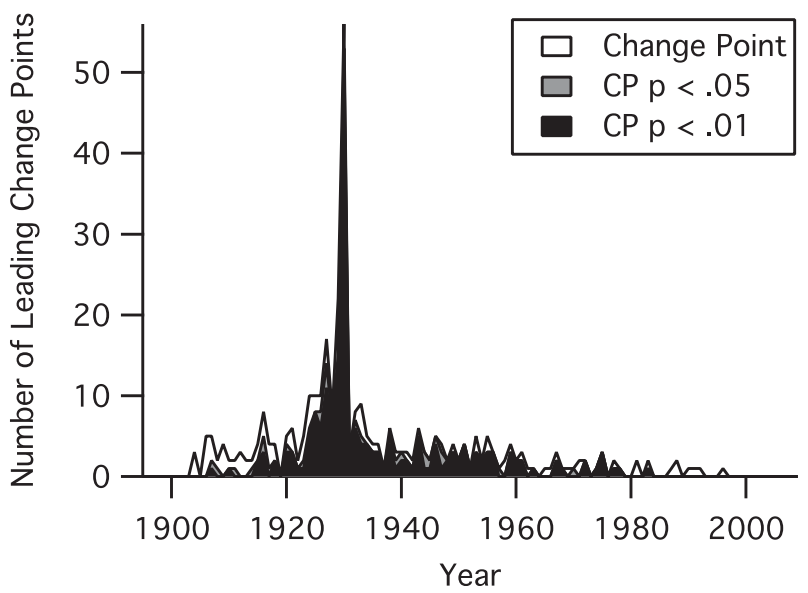

FIG. 2. Number of climate divisions with most prominent changepoint in a given year (white) and those that were statistically significant at $p<0.05$ (gray) and $p<0.01$ (black).

climate divisions have their largest changepoint between 1929 and 1930, which is essentially indistinguishable from a 1930-31 change because of noise in the precipitation differences. The climate divisions having changepoints in these years are scattered throughout the United States (Fig. 1b), with clusters in South Dakota, the eastern Gulf Coast states, and the Northeast. While a few of these changepoints may have been due to changes in station availability, it seems clear from Fig. 2 that most are attributable to the 1931 change in the CDP calculation method.

For example, CDP precipitation in Maine climate division 2 (ME-2) was regularly overestimated relative to the FNEP data prior to 1931, though the year-to-year variations in the FNEP and CDP time series were very similar (Fig. 3). From 1931 to the present, there are no systematic differences in the climate division averages. Because of the positive pre-1931 bias in the ME-2 CDP estimates, the 1895-present linear CDP trend is negative $\left(-3.2 \mathrm{~mm} \mathrm{decade}^{-1}\right.$, or $-3 \%$ century $\left.^{-1}\right)$, whereas the long-term FNEP trend is positive $\left(10.9 \mathrm{~mm} \mathrm{decade}^{-1}\right.$, or $10 \%$ century $\left.^{-1}\right)$. Similarly, the pre-1931 CDP data in South Dakota climate division 3 (SD-3) has a systematic negative bias relative to the FNEP data (Fig. 4), leading to an inflated 1895-present linear CDP trend $\left(12.4 \mathrm{~mm}\right.$ decade $^{-1}$, or $24 \%$ century $\left.^{-1}\right)$. The more modest positive FNEP trend $\left(0.7 \mathrm{~mm}\right.$ decade $^{-1}$, or $1 \%$ century $^{-1}$ ) is probably more representative of actual changes in the SD-3 climate.

The clustering of 1930-31 changepoints in certain regions (Fig. 1b; e.g., Pennsylvania and South Dakota) is likely due to inaccuracies in the pre-1931 statewide regression equations. The regression equations that determined pre-1931 CDP data were based on a finite 


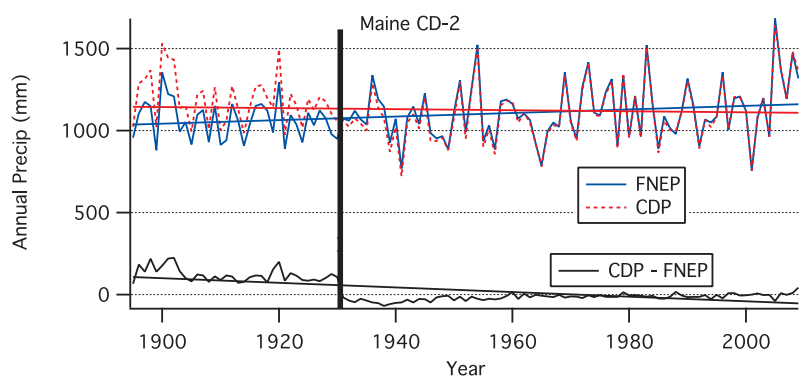

FIG. 3. Time series of the FNEP annual precipitation (blue, solid), the CDP annual precipitation (red, dashed), and the CDP annual precipitation minus the FNEP annual precipitation (black, solid) in ME-2. Also shown are the 1895-present least squares linear trend lines.

training period. If statewide precipitation during this period was uncharacteristic of the normal precipitation climate, the result would be a set of inaccurate regression equations across the state. Additional errors in the pre-1931 CDP could result from inhomogeneities in the stations used to calculate the statewide averages.

\section{c. CDP biases caused by changes in station configuration (1931-present)}

CDP biases not associated with 1930 changepoints can be largely attributed to changes in the temporal configuration of stations, which are used to calculate CDP monthly values. Such artificial biases are especially likely in climate divisions with an inhomogeneous precipitation climate, where a shift in the spatial distribution of stations can change the normal value of a climate division average. The FNEP method addresses this issue by maintaining a constant network of stations in each climate division through the entire period of record.

At any given time, the expected CDP precipitation can be expressed as an equal-weighted average of the expected precipitation at the available stations within the climate division. Investigation of temporal changes in expected CDP precipitation will use the 1971-2000 PRISM normal annual precipitation as the expected precipitation at each station. Each COOP station used in the CDP dataset was assigned the 1971-2000 PRISM normal of the PRISM grid point closest to the location of the station. This method of assigning mean precipitation to each COOP station allows for an unbiased analysis of temporal changes of expected precipitation within climate divisions (Figs. 5 and 6).

Located in the Edwards Plateau of Texas, TX-6 has a large east-west precipitation gradient. The 1971-2000 normal annual precipitation in the eastern Edwards Plateau is as much as $900 \mathrm{~mm} \mathrm{yr}^{-1}$, whereas the normal in areas of the western Edwards Plateau is as little as $300 \mathrm{~mm} \mathrm{yr}^{-1}$ (Daly et al. 2002). During the first half of

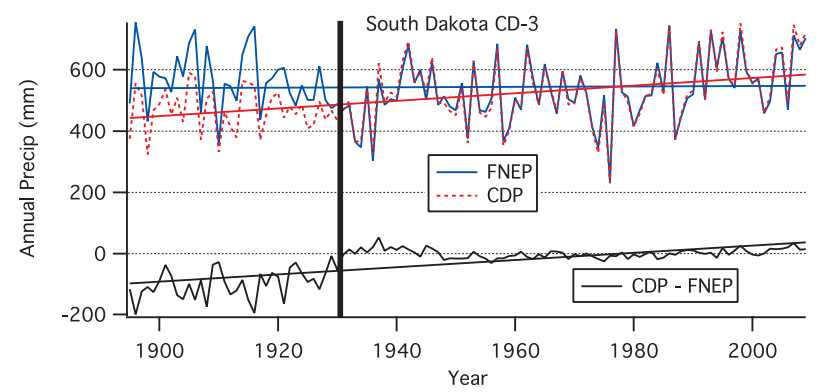

FIG. 4. As in Fig. 3, but for SD-3.

the twentieth century, most COOP stations within TX-6 were located in the eastern half of the climate division. By 1970, they were much more evenly distributed. This overall westward shift of stations lowered the expected TX-6 annual precipitation (Fig. 5) by more than $90 \mathrm{~mm}$ from 1931 to the present and would produce an artificial linear trend in normal precipitation of about -12 to $-14 \mathrm{~mm}$ decade $^{-1}$. Largely because of the decrease in expected precipitation with time in TX-6, the CDP long-term trend is negative $\left(-6.2 \mathrm{~mm}\right.$ decade $^{-1}$, or $-10 \%$ century $^{-1}$ ) and roughly equal in magnitude to the positive TX-6 FNEP trend $\left(+7.6 \mathrm{~mm} \mathrm{decade}^{-1}\right.$, or $+12 \%$ century $^{-1}$ (Fig. 5).

Arizona climate division 1 (AZ-1) is much smaller than TX-6 in geographical area but has a precipitation climate that depends greatly on elevation. The mean elevation of stations within the climate division is closely related to the expected climate division mean annual precipitation (Fig. 6, bottom). Among the 18 COOP stations in AZ-1 with at least 10 years of annual precipitation observations, the two climatologically wettest stations have the highest elevation, while the driest station has the lowest elevation. This is likely the principal cause for the negative CDP long-term trend (Fig. 6), as even the decade-scale variations in the CDP - FNEP difference track the PRISM normals closely. While the CDP trend is negative $\left(-5.3 \mathrm{~mm} \mathrm{decade}^{-1}\right.$, or $-22 \%$ century $^{-1}$ ), the FNEP long-term trend in AZ-1 is slightly positive $\left(+2.1 \mathrm{~mm} \mathrm{decade}^{-1}\right.$, or $+10 \%$ century $^{-1}$ ).

Figure 6 also includes a plot of the PRISM annual precipitation data (Daly et al. 2002) averaged across climate division AZ-1. PRISM climate division data are a true spatial average of the gridded values within a climate division rather than the average precipitation at observing station locations, so there is in general an offset between the PRISM averages and FNEP. Because PRISM is a spatial analysis that attempts to take into account systematic variations associated with elevation and other geographic factors, it should not be very sensitive to station location changes as long as elevation 


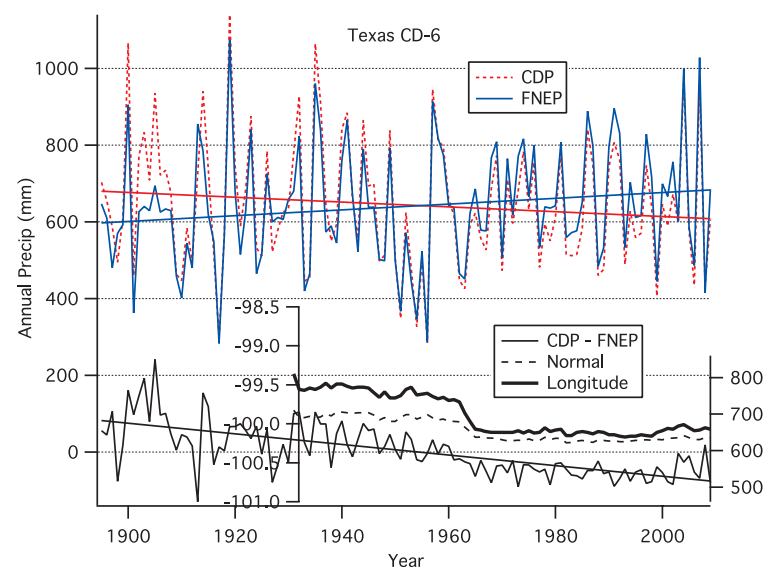

FIG. 5. Time series of the FNEP annual precipitation (blue, solid), the CDP annual precipitation (red, dashed), and the CDP annual precipitation minus the FNEP annual precipitation (black, thin, solid) in TX-6. Also shown are the 1895-present least squares linear trend lines, the expected CDP annual precipitation (black, dashed), and the mean longitude of available stations (black, thick, solid).

dependencies and other factors are handled properly. As with FNEP, the absolute accuracy of the estimates should decrease with loss of stations, as more distant stations are used to estimate particular local values. The strong agreement between the linear trends in FNEP and PRISM, as shown in Fig. 6, implies that both PRISM and FNEP are largely free of biases due to changes in station distribution in AZ-1.

Throughout the western United States (not shown), the PRISM and FNEP trends are, in general, in good agreement in comparison with the CDP trends. Since they use independent techniques to deal with station inhomogeneities, each validates the other.

\section{d. Discussion of long-term trends}

Having determined that the FNEP long-term trends are more reliable than the CDP trends, we now examine them in greater detail. The 1895-present linear trends in FNEP annual precipitation are mostly positive (Fig. 1a), with large areas of precipitation increase greater than $10 \%$ century $^{-1}$ across the southern plains and the Corn Belt. Areas with a small drying trend include the southern Appalachians and parts of the Northwest. Using only long-term stations, Pryor et al. (2009) found a similar pattern of long-term precipitation changes, except in the Northwest where few long-term stations were available. The spatial average of the linear precipitation trend is $6.4 \%$ century $^{-1}$, and the linear trend of the spatial average of precipitation is $6.8 \%$ century $^{-1}$. The corresponding values for CDP are $4.8 \%$ and $6.2 \%$ century $^{-1}$.

As noted earlier, the CDP trends (Fig. 1b) exhibit less spatial consistency, but there are also large regional

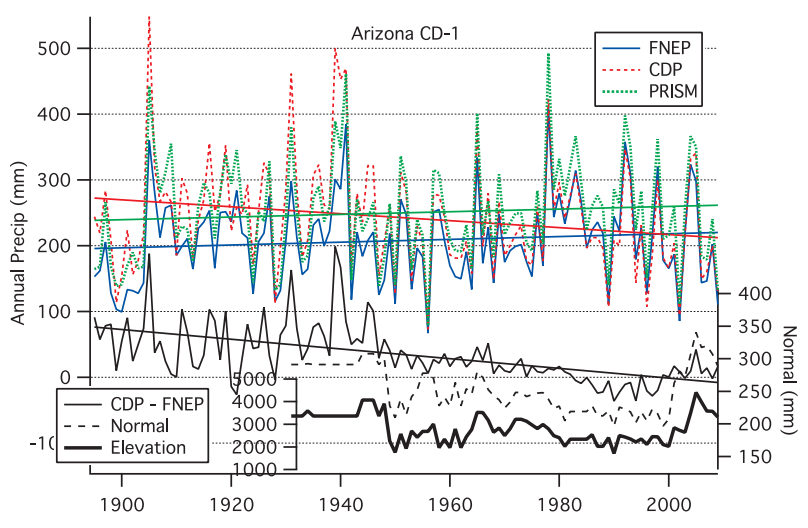

FIG. 6. Time series of the FNEP annual precipitation (blue, solid), the CDP annual precipitation (red, dashed), the PRISM annual precipitation (green, solid), and the CDP annual precipitation minus the FNEP annual precipitation (black, thin, solid) in AZ-1. Also shown are the 1895-present least squares linear trend lines, the expected CDP annual precipitation (black, dashed), and the mean elevation ( $\mathrm{m}$ ) of available stations (black, thick, solid).

differences between CDP and FNEP. Most notably, the CDP trends are negative throughout the northern and central Rocky Mountains and most of California, while the FNEP trends show a slight precipitation increase in the central Rocky Mountains and a general increase over most of California. One possible explanation of the CDP discrepancy would be a spread of farmers and thus COOP volunteers into drier parts of the southwestern United States as irrigation water became more plentiful in this region. While CDP has its most negative Pacific coast trend in southern California, FNEP is negative only along the Oregon and Washington coasts.

The overall precipitation increase in FNEP is consistent with the Intergovernmental Panel on Climate Change (IPCC) conclusion that precipitation on land north of $30^{\circ} \mathrm{N}$ has generally increased (Trenberth et al. 2007). The IPCC report relied upon the Global Historical Climate Network (Peterson and Vose 1997) version-2 monthly precipitation dataset (GHCN-v2), with gridded data available at $5^{\circ} \times 5^{\circ}$ resolution. The gridded GHCN-v2 data are derived from nearly 2200 stations in the contiguous United States, including all 1221 stations in USHCN-v2, and stations in Canada and Mexico.

Figure 7 shows the least squares linear trends in the GHCN-v2 gridded data, computed from 1900 to the present. The long-term trends in FNEP and GHCN-v2 show good agreement in the eastern two-thirds of the United States. Both datasets indicate a small decrease per century in annual precipitation in the Appalachian Mountains, with mostly increasing trends in other areas east of the Continental Divide. Increases in annual 


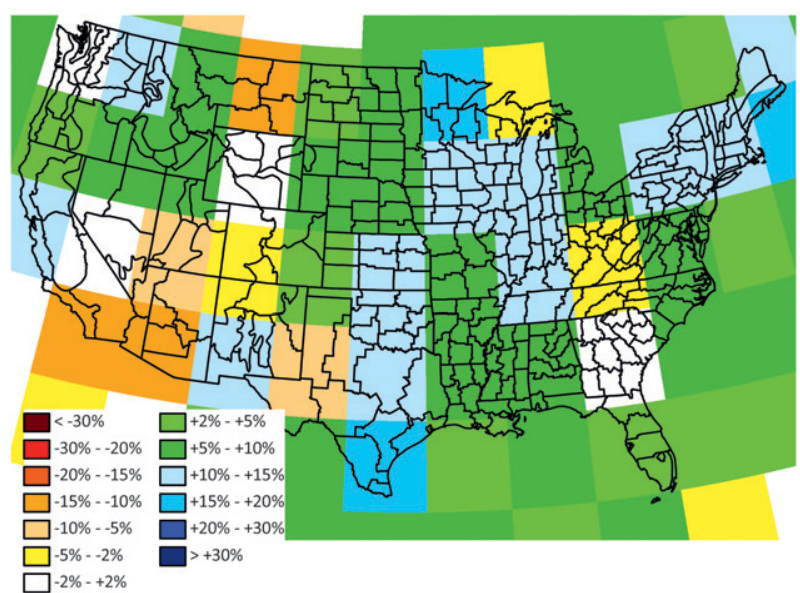

FIG. 7. Linear trends of annual precipitation from 1900 to 2009 for the $\mathrm{GHCN}-\mathrm{v} 25^{\circ} \times 5^{\circ}$ gridded dataset, expressed as percentage change per century.

precipitation of $10 \%-20 \%$ century $^{-1}$ were observed in both datasets in the Corn Belt, the Northeast, and the southern plains.

Disagreements between the FNEP and GHCN-v2 long-term trends are more prevalent in the western United States, particularly in the desert southwest. GHCN-v2 indicates a greater than $10 \%$ decrease in annual precipitation per century in extreme southern California and southwestern Arizona while FNEP indicates an increasing trend in this region. The GHCN-v2 linear trends in the Rocky Mountain region are systematically less than most of the corresponding FNEP climate division trends. The GHCN-v2 long-term trends in the southwest United States and Rocky Mountain region are more similar to the CDP than the FNEP climate division trends.

At this point, the FNEP and GHCN-v2 trends should be viewed as alternative reconstructions of century-scale precipitation variability. They address network changes in different ways, and they utilize different portions of the dataset: GHCN-v2 uses long-duration, generally high-quality stations while FNEP uses all available COOP stations. GHCN-v2 should be more subject to sampling errors because of the smaller number of stations, while FNEP may be more subject to station data quality issues. Further investigation is needed to explore the relative merits of the two approaches for long-term trend analysis.

\section{e. Shorter-term modes of climate variability}

The long-term trends emphasize differences between CDP and FNEP. Correlations or composites of climate division data relative to modes of climate variability such as El Niño-Southern Oscillation are often used as seasonal forecasting tools. To determine whether homogenization would affect the calculation of the climate response to a natural mode of climate variability, FNEP and CDP October-March precipitation were regressed against July-November Southern Oscillation index (SOI) values (Australian Government Bureau of Meteorology 2010). A strong correlation between these two variables was found by Redmond and Koch (1991).

Among those climate divisions with a statistically significant correlation between FNEP or CDP precipitation and SOI values, the correlation tended to be larger for FNEP. The average magnitude of the correlation difference was small, however: about 0.005 . So while the differences are slight, the FNEP data contain a clearer spatial signal of climate variability than does the CDP data.

\section{Climate variance and drought assessment}

The use of climate division data for drought monitoring and assessment is widespread (see, e.g., Svoboda et al. 2002). Not only are historical changes of drought intensity of interest (e.g., Easterling et al. 2007), but many drought indices such as the standardized precipitation index (McKee et al. 1993) require a reliable historical record of drought severity. This, in turn, requires that the historical dataset not be subject to inhomogeneities that cause changes in the variance of accumulated precipitation. If historical variance is artificially low, for example, a current drought will seem artificially extreme.

Climate division data are likely to suffer from such an inhomogeneity. A variance discontinuity is to be expected in the CDP records at the 1931 changepoint in methodology, but before and after that date, changes in the number of stations will have affected the variance. The more stations being used to construct the average precipitation value for a climate division, the smaller the expected variance, as random differences caused by small-scale precipitation events are averaged out. To our knowledge, existing drought monitoring techniques that use climate division data do not correct for these inhomogeneities.

Although the FNEP dataset maintains a uniform number of stations, the missing station data are estimated from a weighted average of 13 neighbors. This will cause the estimated data to tend to have smaller variance than actual station data. Many of the stations going into the weighted averages are actually outside the climate division of the target station, so the averaging involves a larger area than just the climate division. As a result, FNEP data should have smaller variance early in the period of record when precipitation monitoring 


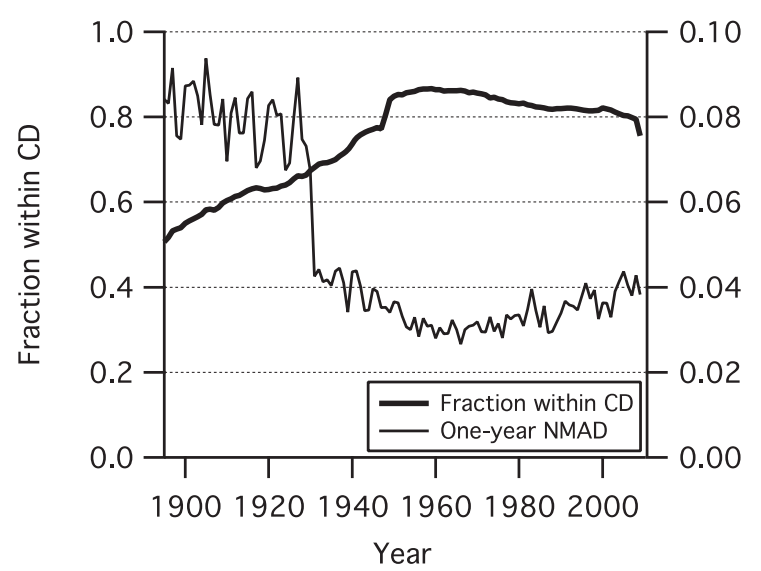

FIG. 8. Fraction of FNEP climate division annual average obtained from observations within the climate division (thick line). Normalized mean absolute difference between CDP and FNEP annual precipitation, averaged across all climate divisions (thin line).

stations were relatively sparse, and larger variance since 1948 when the COOP network attained its modern density.

A sense of the time dependence of the smoothing may be obtained from a calculation of the average fraction of the FNEP climate division average arising from data outside the climate division (Fig. 8). For example, if a climate division has nine reporting stations and one missing station, and the estimation of the missing precipitation value weights observations within and outside of the climate division equally, $0.1 \times 0.5=0.05$ of the FNEP average is created from observations outside the climate division, and the fraction of the FNEP climate division average obtained from observations within the climate division is 0.95 . The smaller this fraction, the greater is the effective smoothing.

An estimate of the resulting variance inhomogeneity may be made by comparing pre-1931 and post-1947 precipitation variance with a control dataset assumed to have little or no variance inhomogeneity: the USHCN-v2 precipitation observations. To measure overall changes in variance, the variances within each climate division were divided by the average post-1947 variance of USHCN-v2 stations within the same climate division. The results are shown in Table 6.

Both climate division datasets, being averages of station precipitation, have smaller variance than the USHCN-v2 station data. During 1948-2009, the CDP and FNEP variances are similar, with FNEP being slightly smaller because it includes additional estimated values not present in CDP. Both CDP and FNEP have smaller variances in the earlier (1895-1930) period, with the change in variance exceeding that of the USHCN-v2 data. The artificial decline is largest for CDP, implying
TABLE 6. Average normalized variance of annual precipitation for the periods indicated. Variance is normalized within a climate division by the average 1948-2009 annual precipitation variance of all USHCN-v2 stations in the climate division. The ratio is computed as the 1895-1930 variance divided by the 1948-2009 USHCN-v2 variance.

\begin{tabular}{lccc}
\hline \hline Period & USHCN-v2 & CDP & FNEP \\
\hline $1895-1930$ & 0.89 & 0.59 & 0.61 \\
1948-2009 & 1 & 0.74 & 0.73 \\
Ratio & 0.89 & 0.80 & 0.83 \\
\hline
\end{tabular}

that the FNEP dataset is more suitable for drought monitoring and assessment than the CDP data. Because the FNEP variance change is $17 \%$ and the USHCN-v2 variance change is $11 \%$, we conclude that FNEP includes an artificial $6 \%$ suppression of variance in the 1895-1930 period.

The overall differences between the CDP and FNEP precipitation values are also dependent upon the extent to which FNEP utilizes stations within the same climate division. The normalized mean absolute differences between CDP and FNEP annual precipitation values, also shown in Fig. 8, indicate that the agreement between the two datasets is largest when the greatest fraction of in-division data are used in FNEP. The agreement between CDP and FNEP is considerably worse prior to 1931 for reasons discussed earlier.

\section{Summary}

The FNEP climate division precipitation dataset has been constructed to utilize data from as many COOP stations as possible and to avoid inhomogeneities associated with changes in the network configuration of stations within a climate division. The FNEP data are more representative of observed station precipitation within a climate division than the existing NCDC climate division precipitation data, according to data-withholding experiments. The FNEP data are also consistent with the interannual variability and long-term trends produced from the PRISM technique, which, like FNEP, should be relatively insensitive to changes in station configuration.

The long-term precipitation trends computed using FNEP have major differences with the CDP trends in many parts of the United States. Many of these differences are caused by inhomogeneities introduced into the CDP data because the algorithm for computing pre-1931 CDP data differs from the post-1931 algorithm. Other differences are consistent with known changes in the station configuration and expected changes in climate division-averaged normal precipitation that would result from those changes. 
We recommend that the FNEP data be used in place of the CDP data for studies involving long-term trends. (The FNEP dataset is available online at http://atmo. tamu.edu/osc/fnep.) The FNEP data are slightly better than CDP for diagnosing precipitation responses to largescale modes of climate variability. Because artificial changes of variance are smaller with the FNEP data than the CDP, the FNEP data are also better suited for diagnosing and assessing drought intensity. Differences between FNEP and CDP data are especially large prior to 1931.

The FNEP trends are generally consistent with the coarser-gridded trends in the GHCN-v2 dataset, but some important differences exist, primarily in the southwestern United States. The FNEP data indicate an overall increase in conterminous U.S. precipitation of $6 \%-7 \%$ century $^{-1}$. More rapid increases, exceeding $10 \%$ century $^{-1}$, are found in much of the south-central United States, the Corn Belt, parts of the Northeast, and parts of the Intermountain West. Slight decreasing trends are found primarily in the southern Appalachians and Piedmont, parts of Montana and Wyoming, and coastal areas of the Pacific Northwest.

It should be kept in mind that these trends are of observed precipitation; changes in techniques for measuring precipitation may introduce an artificial aspect to these trends (Karl et al. 1993). In particular, trends may be least trustworthy in colder parts of the United States because of difficulties in measuring snowfall in cold, windy conditions. According to Metcalfe et al. (1997), network-wide upgrades in the Canadian measurement network produced a $15 \%$ increase in measured precipitation due to decreased evaporation and wetting losses, so inhomogeneities caused by gauge replacement can be important. Over the United States, Groisman and Easterling (1994) found that, within a subset of USHCN stations considered to have the most homogeneous data, the linear increase of precipitation in the conterminous United States from 1891 to 1990 was $4 \%$ century $^{-1}$. The FNEP average trend over almost the same period (1895-1990) was $5.2 \%$ century $^{-1}$, implying a possible FNEP trend bias of $1.2 \%$, but the Groisman and Easterling (1994) stations were located predominantly in areas with relatively large trends according to the FNEP data, so the trend bias may be larger. Karl et al. (1993) note that most stations in the COOP network have not undergone major siting or precipitation gauge inhomogeneities, and that the artificial trend due to inhomogeneities at primary weather stations is likely to be negative. We therefore estimate the overall FNEP trend bias due to station inhomogeneities to be on the order of $1 \%-3 \%$.

Acknowledgments. The authors are grateful for the comments of Kelly Redmond and Russell Vose, which proved valuable in the completion of this manuscript. Additionally, we thank the three reviewers for their helpful input.

\section{REFERENCES}

Alexandersson, H., 1986: A homogeneity test applied to precipitation data. Int. J. Climatol., 6, 661-675.

Allard, J., B. D. Keim, J. E. Chassereau, and D. Sathiaraj, 2008: Spuriously induced precipitation trends in the southeast United States. Theor. Appl. Climatol., 96, 173-177.

Australian Government Bureau of Meteorology, cited 2010: S.O.I. (Southern Oscillation Index) Archives: 1876 to present. [Available online at http://www.bom.gov.au/climate/current/ soihtm1.shtml.]

Buishand, T. A., 1982: Some methods for testing the homogeneity of rainfall records. J. Hydrol., 58, 11-27.

Cressman, G. P., 1959: An operational objective analysis system. Mon. Wea. Rev., 87, 367-374.

Daly, C., W. P. Gibson, G. H. Taylor, G. L. Johnson, and P. Pasteris, 2002: A knowledge-based approach to the statistical mapping of climate. Climate Res., 22, 99-113.

Di Luzio, M., G. L. Johnson, C. Daly, J. Eischeid, and J. G. Arnold, 2008: Constructing retrospective gridded daily precipitation and temperature data sets for the conterminous United States. J. Appl. Meteor. Climatol., 47, 475-497.

Easterling, D. R., T. W. R. Wallis, J. H. Lawrimore, and R. R. Heim Jr., 2007: Effects of temperature and precipitation trends on U.S. drought. Geophys. Res. Lett., 34, L20709, doi:10.1029/ 2007GL031541.

Eischeid, J. K., C. B. Baker, T. R. Karl, and H. F. Diaz, 1995: The quality control of long-term climatological data using objective data analysis. J. Appl. Meteor., 34, 2787-2795.

- P. A. Pasteris, H. F. Diaz, M. S. Plantico, and N. J. Lott, 2000: Creating a serially complete, national daily time series of temperature and precipitation for the western United States. J. Appl. Meteor., 39, 1580-1591.

Goodrich, G. B., and A. W. Ellis, 2006: Climatological drought in Arizona: An analysis of indicators for guiding the governor's drought task force. Prof. Geogr., 58, 460-469.

Grantz, K., B. Rajagopalan, M. Clark, and E. Zagona, 2007: Seasonal shifts in the North American monsoon. J. Climate, 20, 1923-1935.

Groisman, P. Ya., and D. R. Easterling, 1994: Variability and trends of total precipitation and snowfall over the United States and Canada. J. Climate, 7, 184-205.

Grundstein, A., 2008: Assessing climate change in the contiguous United States using a modified Thornthwaite climate classification scheme. Prof. Geogr., 60, 398-412.

Guttman, N. B., and R. G. Quayle, 1996: A historical perspective of U.S. climate divisions. Bull. Amer. Meteor. Soc., 77, 293-303.

Hulme, M., and M. New, 1997: Dependence of large-scale precipitation climatologies on temporal and spatial sampling. J. Climate, 10, 1099-1113.

Jones, P. D., and M. Hulme, 1996: Calculating regional climatic time series for temperature and precipitation: Methods and illustrations. Int. J. Climatol., 16, 361-377.

Karl, T. R., and R. W. Knight, 1998: Secular trends of precipitation amount, frequency, and intensity in the United States. Bull. Amer. Meteor. Soc., 79, 231-241.

_ R. R. Quayle, and P. Ya. Groisman, 1993: Detecting climate variations and change: New challenges for observing and data management systems. J. Climate, 6, 1481-1494. 
Keim, B. D., M. R. Fischer, and A. M. Wilson, 2005: Are there spurious precipitation trends in the United States climate division database? Geophys. Res. Lett., 32, L04702, doi:10.1029/ 2004GL021985.

Kumar, M., and C. J. Duffy, 2009: Detecting hydroclimatic change using spatio-temporal analysis of time series in Colorado River Basin. J. Hydrol., 374, 1-15, doi:10.1016/j.jhydrol.2009.03.039.

Kunkel, K. E., K. Andsager, and D. R. Easterling, 1999: Long-term trends in extreme precipitation events over the conterminous United States and Canada. J. Climate, 12, 2515-2527.

Kurtzman, D., and B. R. Scanlon, 2007: El Niño-Southern Oscillation and Pacific Decadal Oscillation impacts on precipitation in the southern and central United States: Evaluation of spatial distribution and predictions. Water Resour. Res., 43, W10427, doi:10.1029/2007WR005863.

Leathers, D. J., A. J. Grundstein, and A. W. Ellis, 2000: Growing season moisture deficits across the northeastern United States. Climate Res., 14, 43-55.

McCabe, G. L., M. A. Palecki, and J. L. Betancourt, 2004: Pacific and Atlantic Ocean influences on multidecadal drought frequency in the United States. Proc. Natl. Acad. Sci. USA, 101, 4136-4141.

McKee, T. B., N. J. Doesken, and J. Kleist, 1993: The relationship of drought frequency and duration to time scale. Preprints, Eighth Conf. on Applied Climatology, Anaheim, CA, Amer. Meteor. Soc., 179-184.

Menne, M. J., C. M. Williams Jr., and R. S. Vose, 2009: The U.S. Historical Climatology Network monthly temperature data, version 2. Bull. Amer. Meteor. Soc., 90, 993-997.

Metcalfe, J. R., B. Routledge, and K. Devine, 1997: Rainfall measurement in Canada: Changing observational methods and archive adjustment procedures. J. Climate, 10, 92-101.

Mosmann, V., A. Castro, R. Fraile, J. Dessens, and J. L. Sanchez, 2004: Detection of statistically significant trends in the summer precipitation of mainland Spain. Atmos. Res., 70, 43-53.

New, M., M. Hulme, and P. D. Jones, 1999: Representing twentiethcentury space-time climate variability. Part I: Development of a 1961-90 mean monthly terrestrial climatology. J. Climate, 12, 829-856.

Paulhus, J. L. H., and M. A. Kohler, 1952: Interpolation of missing precipitation records. Mon. Wea. Rev., 80, 129-133.

Peterson, T. C., and D. R. Easterling, 1994: Creation of homogenous composite climatological reference series. Int. J. Climatol., 14, 671-679.
, and R. S. Vose, 1997: An overview of the Global Historical Climatology Network temperature database. Bull. Amer. Meteor. Soc., 78, 2837-2850.

_ _ and Coauthors, 1998: Homogeneity adjustments of in situ atmospheric climate data: A review. Int. J. Climatol., 18, 14931517.

Pielke, R., Sr., and Coauthors, 2007: Documentation of uncertainties and bias associated with surface temperature measurement sites for climate change assessment. Bull. Amer. Meteor. Soc., 88, 913-928.

Pryor, S. C., J. A. Howe, and K. E. Kunkel, 2009: How spatially coherent and statistically robust are temporal changes in extreme precipitation in the contiguous USA? Int. J. Climatol., 29, 31-45, doi:10.1002/joc.1696.

Redmond, K. T., and R. W. Koch, 1991: Surface climate and streamflow variability in the western United States and their relationship to large-scale circulation indices. Water Resour. Res., 27, 2381-2399.

Seager, R., A. Tzanova, and J. Nakamura, 2009: Drought in the southeastern United States: Causes, variability over the last millennium, and the potential for future hydroclimate change. J. Climate, 22, 5021-5045.

Serbin, S. P., and C. J. Kucharik, 2009: Spatiotemporal mapping of temperature and precipitation for the development of a multidecadal climatic data set for Wisconsin. J. Appl. Meteor. Climatol., 48, 742-757.

Sheppard, P. R., A. C. Comrie, G. D. Packin, K. Angersbach, and M. K. Hughes, 2002: The climate of the U.S. Southwest. Climate Res., 21, 219-238.

Suhaila, J., M. D. Sayang, and A. A. Jemain, 2008: Revised spatial weighting methods for estimation of missing rainfall data. Asia-Pac. J. Atmos. Sci., 44, 93-104.

Sun, B., and T. C. Peterson, 2005: Estimating temperature normals for USCRN stations. Int. J. Climatol., 25, 1809-1817.

Svoboda, M., and Coauthors, 2002: The drought monitor. Bull. Amer. Meteor. Soc., 83, 1181-1190.

Trenberth, K. E., and Coauthors, 2007: Observations: Surface and atmospheric climate change. Climate Change 2007: The Physical Science Basis, S. Solomon et al., Eds., Cambridge University Press, 235-336.

Young, K. C., 1992: A three-way model for interpolating for monthly precipitation values. Mon. Wea. Rev., 120, 25612569. 